\title{
Investigation of the Thermo-Mechanical Properties of Blend Films Based on Hemicelluloses and Cellulose
}

\author{
Hui Gao, Jun Rao, Ying Guan $(D$, Wen-qi Li, Mao-chao Zhang, Ting Shu, and Zi-wen Lv \\ Forestry and Landscape Architecture, Anhui Agricultural University, Hefei 230036, China \\ Correspondence should be addressed to Ying Guan; xiaomi1231@163.com
}

Received 16 April 2018; Revised 13 June 2018; Accepted 28 June 2018; Published 24 July 2018

Academic Editor: Yun-yan Wang

Copyright @ 2018 Hui Gao et al. This is an open access article distributed under the Creative Commons Attribution License, which permits unrestricted use, distribution, and reproduction in any medium, provided the original work is properly cited.

\begin{abstract}
This study presents an effective and convenient approach to prepare blend films with enhanced mechanical and thermodynamic properties by incorporation of carboxymethyl cellulose (CMC) into quaternized hemicelluloses (QH). The structures and properties of films were analyzed by Fourier transform infrared spectroscopy (FTIR), X-ray diffraction (XRD), scanning electron microscopy (SEM), and tensile testing, respectively. From the SEM pictures, tight, homogeneous, and smooth surfaces of films were obtained. In addition, the transparencies of the blend films were increased with the increasing of CMC content. The results of mechanical properties indicated that the blend film prepared from QH and CMC $(1: 2 \mathrm{~m} / \mathrm{m})$ had a tensile strength of 65.2 MPa. It suggested that the addition of CMC was contributed to mechanical properties by strong electrostatic interactions and the enhanced hydrogen bondings with $\mathrm{QH}$. These results provide insights into the understanding of the structural relationships of bioblend films in coating and packaging application.
\end{abstract}

\section{Introduction}

Sustainable sources of materials are pressing needed to supply the demands of society in the future with the increasing awareness of the limited fossil fuels [1-3]. To resolve this problem, more attentions have been focused on biomass materials. Biomass materials are regarded as promising materials that can be replaced synthetic polymer based on petroleum [4]. Biomass is the most abundant lignocellulose that consists mainly of cellulose, hemicelluloses, and lignin [5]. In those materials, cellulose and hemicelluloses have been widely applied due to their biocompatibility, biodegradability, potential film forming, and nonpoisonous content [6-8].

The molecular structure of cellulose endowed its fantastic characteristic: hydrophilicity, chirality, degradability, and broad chemical variability initiated by the high reactivity of the $\mathrm{OH}$ groups [9]. As a functional biopolymer, various derivatives of cellulose have been synthesized and used in many practical applications. Among the derivatives, carboxymethyl cellulose shows amphiphilic characteristics due to it contains a hydrophobic polysaccharide backbone and many hydrophilic carboxyl groups [10]. It is important that anionic polysaccharide has been widely used as a highly effective additive to improve product and processing properties in many fields, such as cosmetics, foodstuffs, and pharmaceuticals [11]. Therefore, the films prepared from CMC have a widespread application in the future.

Hemicelluloses are generally defined as the noncellulose polysaccharides in plant cell wall and represent about $20 \%-40 \%$ of the biomass, which consists of pentoses, hexoses, and sugar acid [12]. Unlike cellulose, hemicelluloses are generally identified as noncrystalline and branched polymer of low molecular weight with a degree of polymerization of 80-200 in their nature state [13]. The previous researches have shown that hemicellulose-based films have good gas barrier properties and excellent oxygen barrier properties $[14,15]$. However, there are some problems that need to be urgently overcome, such as being hydrophilic, poor thermal stability, and flexibility [16]. In order to improve hemicellulose utilization ratio and broaden its application, chemical modification is necessary $[17,18]$. It is reported that hemicelluloses can be chemically modified and then transformed into types of functional polymers, such as cationic hemicelluloses [19-21], carboxymethyl hemicelluloses [22-24], and 


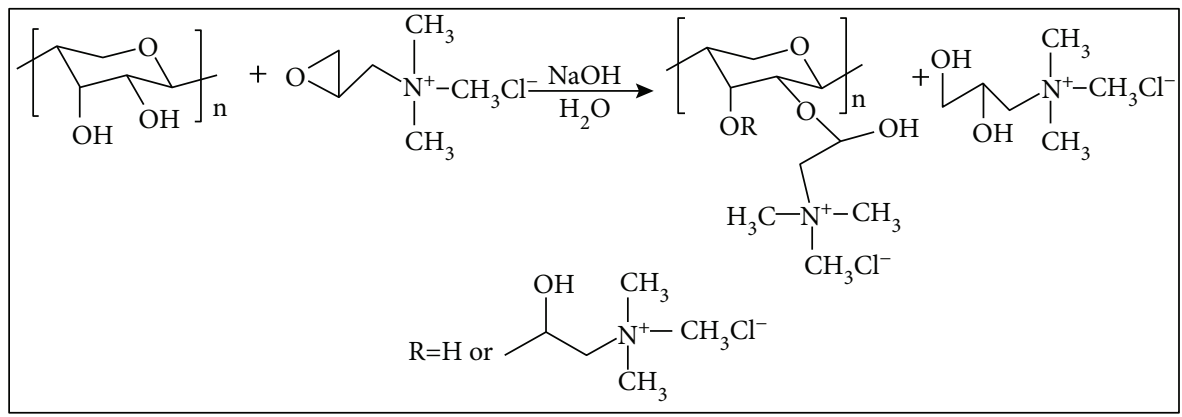

Scheme 1: Etherification of bamboo hemicelluloses.

oleoylated hemicelluloses $[25,26]$. In the modified polymers, quaternization of hemicelluloses will increase their solubility and being cationic and ampholytic because of the cationic groups and hydroxyl radical [27]. Therefore, quaternized hemicelluloses can be used for the preparation of film.

To take full advantages of the CMC and $\mathrm{QH}$, blending is an effective pathway for fabricating films. The two biopolymers can endow blend films' new properties and broaden their applications by conventional processing techniques $[28,29]$. In our previous study, blend films were prepared successfully by this method [30], and the blend films exhibited high transmittance and good barrier properties. However, the mechanical property of film was not good enough for packing use, and the thermodynamics property of the film had not been detected. In this study, a suite of novel blend films was prepared from two biopolymers $(\mathrm{QH}$ and $\mathrm{CMC}$ ) according to a predetermined ratio. The structure of the film was investigated by FTIR and XRD analyses, and the SEM technologies were used to detect the morphology of the blend films. The mechanical properties and light transmissions of films were analyzed by dynamic mechanical analysis (DMA), thermal gravimetric analysis (TGA), tension test, and UV/Vis spectrophotometer, respectively.

\section{Materials and Methods}

2.1. Material. The hemicelluloses were obtained from bamboo (Huoshan, Anhui province, China) by alkaline extraction method [31]. Hemicelluloses were modified according to the literature described by Ren et al. [32] (Scheme 1). The quaternized hemicelluloses had a weight average molecular weight $(\mathrm{Mw})$ of $9240 \mathrm{~g} \cdot \mathrm{mol}^{-1}$, which was obtained by gel permeation chromatography (GPC). The degree of substitution (DS) of the modified hemicelluloses was 0.45 by a titration method according to the previously study [21]. 2,3-Epoxypropyltrimethyl ammonium chloride (ETA) was obtained from Shanghai Dibo Chemical Co., China. Carboxymethyl cellulose was acquired from Cheng Du Long Ke Fine Chemical Co. Ltd., China. The weight average molecular weight $(\mathrm{Mw})$ of CMC is $29,500 \mathrm{~g} \cdot \mathrm{mol}^{-1}$, and the viscosity is $1200 \mathrm{~Pa} \cdot \mathrm{s}$. The PE (the modern is M100, Miao Jie) was acquired from the supermarket. All the reagents used in the experiment were analytical grade and used without any further purification.
TABLE 1: Composition of the blend films.

\begin{tabular}{lcc}
\hline Sample & QH: CMC $(\mathrm{m} / \mathrm{m})$ & Components of CMC (wt\%) \\
\hline Film 1 & $1: 1$ & 50 \\
Film 2 & $1: 2$ & 66.7 \\
Film 3 & $2: 1$ & 33.3 \\
\hline
\end{tabular}

2.2. Preparation of Blend Films. The obtained quaternized hemicelluloses were combined with carboxymethyl cellulose, according to the procedure of Qi et al. [30]. In brief, the solution of quaternized hemicelluloses $(1.5 \mathrm{wt} \%)$ was prepared at $25^{\circ} \mathrm{C}$ for $12 \mathrm{~h}$ under mechanical stirring. Then, the solution was centrifuged for $10 \mathrm{~min}$, and the supernatant was stored in refrigerator at $3^{\circ} \mathrm{C}$. The obtained insoluble parts were dried to calculate the concentration of the supernatant. CMC was dissolved in distilled water at $60^{\circ} \mathrm{C}$ for 30 min under magnetic stirring to prepare the solution with concentration of $1.5 \mathrm{wt} \%$. A fifteen-milliliter-mixing solution was used for preparing each film, and the different mass ratios of the two polymers and components of CMC are shown in Table 1. Then, the solutions were mixed under magnetic stirring at air condition for $24 \mathrm{~h}$. After that, the mixing solution was casted into plastic Petri dish and dried under ambient temperature for 7 days. Finally, the films were peeled off from the dishes carefully.

2.3. Characterization. FTIR spectra of $\mathrm{QH}, \mathrm{CMC}$, and $\mathrm{QH} / \mathrm{CMC}$ blend films were recorded on a Bruker Optik $\mathrm{GmbH}$ Tensor II equipment (Bruker, Germany). QH and CMC powders were prepared by grinding with potassium bromide and laminating. The weight of specimens and potassium bromide was $1 \mathrm{mg}$ and $0.1 \mathrm{~g}$, respectively. The film samples were measured under the ATR mode. FTIR spectra were recorded on the spectrum range of $4000-500 \mathrm{~cm}^{-1}$. The diffraction patterns of $\mathrm{QH}, \mathrm{CMC}$, and blend films were measured by a $6000 \mathrm{X}$-ray diffractometer (Shimadzu, Kyoto, Japan), using nickel-filtered $\mathrm{Cu} \mathrm{K} \alpha$ radiation $(\lambda=0.154 \mathrm{~nm})$ at $36 \mathrm{kV}$ and $30 \mathrm{~mA}$ in the $2 \theta$ range of $5^{\circ}-45^{\circ}$ with a speed of $2^{\circ} / \mathrm{min}$. The morphologies of film samples were investigated by field emission scanning electron microscopy using a Hitachi S-4800 (Hitachi, Japan) instrument at $15 \mathrm{kV}$. Prior to SEM observation, the specimen samples were sputter-coated with a thin layer of gold, and the cross-sections of the blend films 


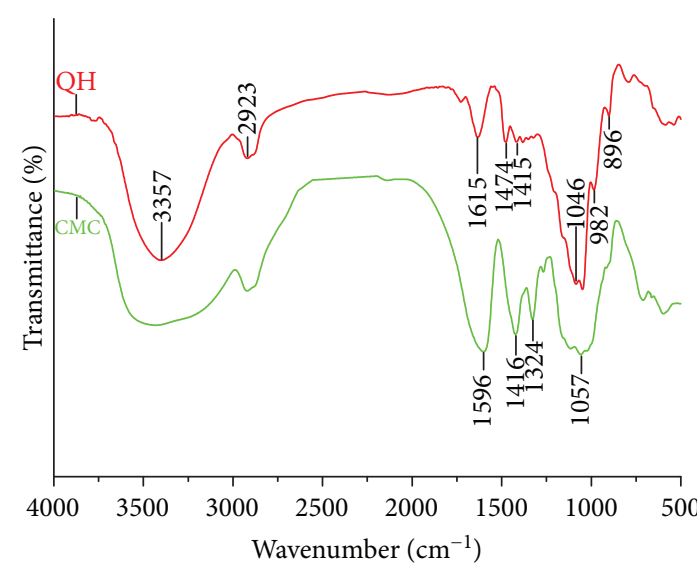

(a)

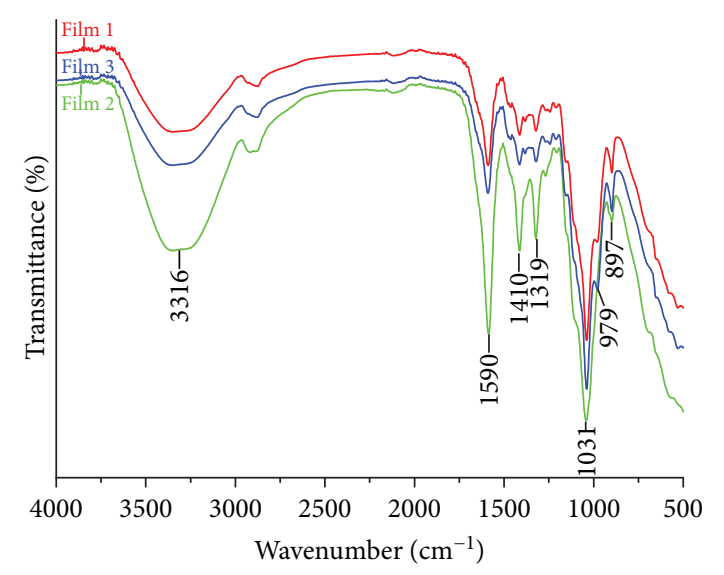

(b)

FIGURE 1: FTIR spectra of QH and CMC (a). FTIR spectra of the representative blend films (b).

gained in liquid nitrogen by brittle fractured. UV-Vis spectra of sample films were obtained by an ultraviolet/visible spectrophotometer (PG Instruments TU-1900) within the range of $200-800 \mathrm{~nm}$. The thicknesses of films were performed by paper thickness gauge (ZH-4, Changchun Paper Testing Machine Co. Ltd., China). The results for each film were based on at least five specimens.

2.4. Thermal Gravimetric Analysis. The thermal gravimetric analyses of films were characterized by TGA analyzer (TG209, NETZSCH) under a nitrogen atmosphere. The heating rate was $10^{\circ} \mathrm{C} / \mathrm{min}$, and the temperature was from 35 to $700^{\circ} \mathrm{C}$. The obtained films were previously dried at $40^{\circ} \mathrm{C}$ before the TGA analyses.

2.5. Dynamic Mechanical Analysis. The dynamic mechanical property of film was performed with a DMA Model 242 E/1/G (NETZSCH, Germany) in the film-tension mode. Sample dimensions were approximately $30 \mathrm{~mm}$ length, $2 \mathrm{~mm}$ width, and $50 \mu \mathrm{m}$ thickness. Samples were heated from -50 to $180^{\circ} \mathrm{C}$ at $2^{\circ} \mathrm{C} / \mathrm{min}$ (static strain of $0.67 \%, 20 \mu \mathrm{m}$ amplitude, $1 \mathrm{~Hz}$ ). The films were preconditioned at $25^{\circ} \mathrm{C}$ and $60 \%$ $\mathrm{RH}$ for at least $48 \mathrm{~h}$ prior to the testing to make sure the moisture content of each sample is equalized.

2.6. Tensile Properties. The tensile test of the films was performed by a universal material testing machine with a load cell of $1 \mathrm{kN}$ (AG-X plus, Shimadzu, Kyoto, Japan). Specimens of $20 \mathrm{~mm}$ length and $40-60 \mu \mathrm{m}$ thickness and $2.5 \mathrm{~mm}$ width were tested with strain rate of $5 \mathrm{~mm} / \mathrm{min}$. At least three repeated measurements of each film were tested, and the average value was used to determine mechanical properties.

\section{Results and Discussion}

3.1. FTIR Analysis. The FTIR spectra of quaternized hemicelluloses and carboxymethyl cellulose are illustrated in Figure 1(a). As can be seen, the signals presented at 1615, 1474,1046 , and $896 \mathrm{~cm}^{-1}$ are the characteristic peaks of QH. The bands at 3357 and $2923 \mathrm{~cm}^{-1}$ are indicatives of the stretching of the $\mathrm{OH}$ groups and $\mathrm{C}-\mathrm{H}$ vibration band, respectively. The peak at $896 \mathrm{~cm}^{-1}$ is a characteristic of $\beta$-glucosidic

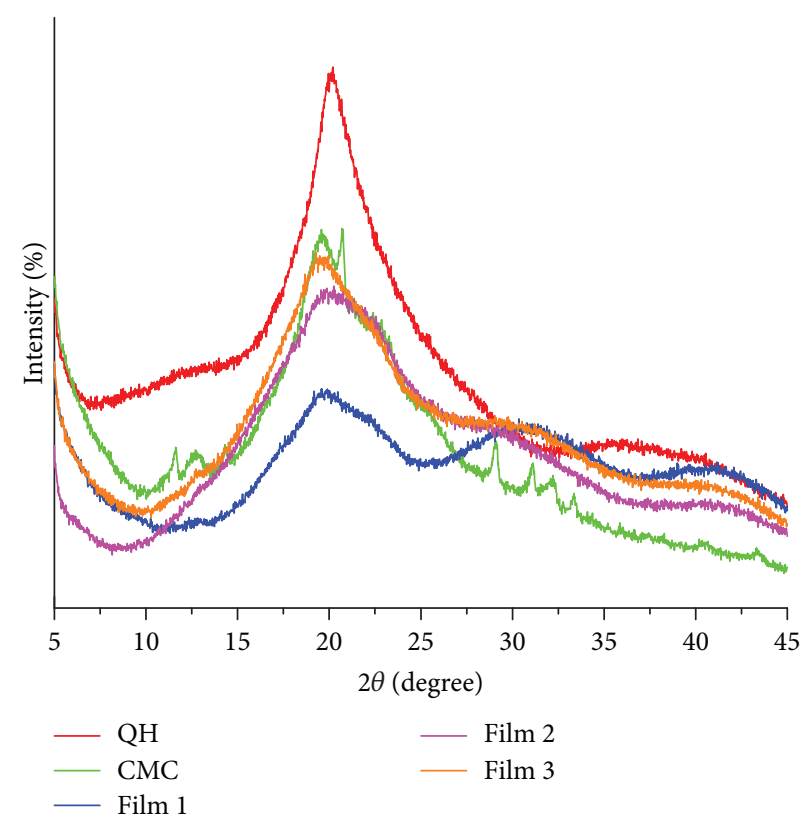

FIgURE 2: X-ray diffraction patterns of QH, CMC, and blend films.

linkages between the xylose units. The signal at $1615 \mathrm{~cm}^{-1}$ is originated from - $\mathrm{COO}$ - of uronic acid and uronic carboxylate in hemicelluloses [33]. The absorption peak at $1474 \mathrm{~cm}^{-1}$ appeared in $\mathrm{QH}$ is originated from the bending vibration of $-\mathrm{CH}_{3}$ and $-\mathrm{CH}_{2}$ in quaternary ammonium group [34]. In the spectrum of CMC, the absorption band at $1596 \mathrm{~cm}^{-1}$ is assigned to asymmetrical COO- stretching [35]. The signals at 1416 and $1324 \mathrm{~cm}^{-1}$ are related to the symmetrical stretching vibrations of the carboxylate groups and $\mathrm{C}-\mathrm{H}$ bending, respectively [36]. The broad peak at $1057 \mathrm{~cm}^{-1}$ is assigned to the stretching of $\mathrm{C}-\mathrm{O}-\mathrm{C}$ [37]. The spectra of blend films are shown in Figure 1(b). Compared of QH and $\mathrm{CMC}$, the peak of the $\mathrm{C}-\mathrm{O}-\mathrm{C}$ was narrowed and shifted evidently from 1057 to $1031 \mathrm{~cm}^{-1}$. The absorption peaks at 1590 and $897 \mathrm{~cm}^{-1}$ of blend films are attributed to asymmetrical COO- stretching and $\beta$-glycosidic bond, respectively. It can be found that no chemical reaction occurred between $\mathrm{QH}$ 


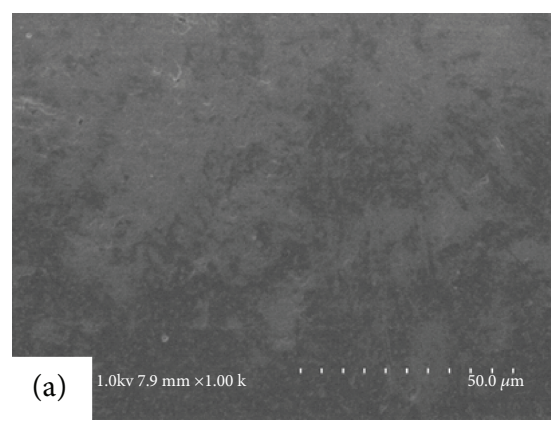

(a)

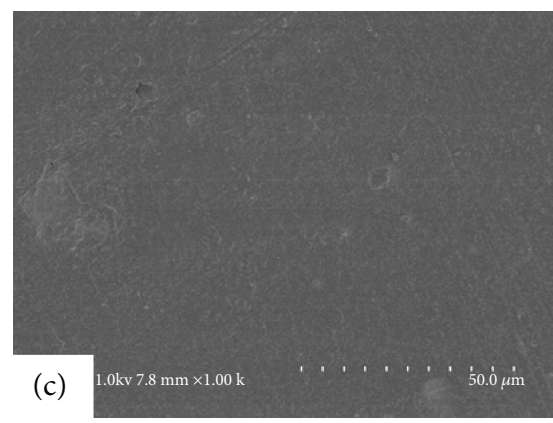

(c)

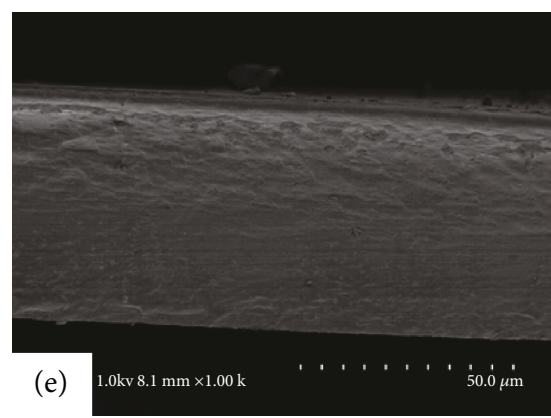

(e)

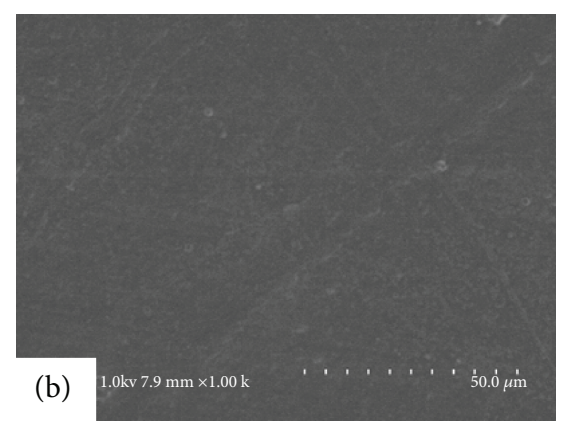

(b)

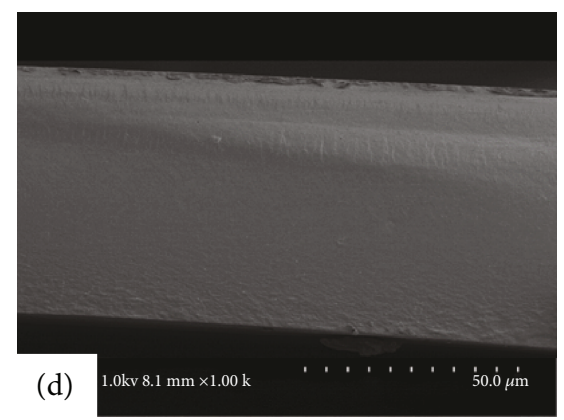

(d)

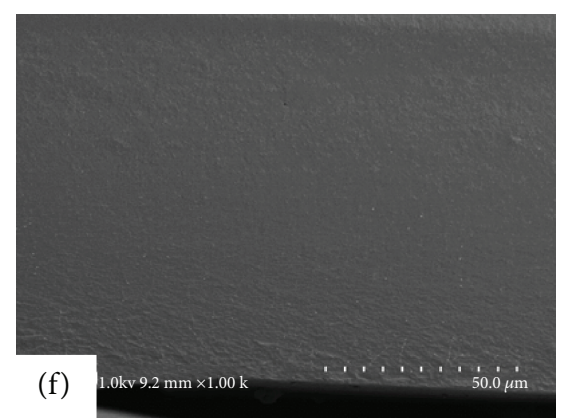

(f)

Figure 3: SEM images of film 1 ((a) surface and (d) cross section), film 2 ((b) surface and (e) cross section), and film 3 ((c) surface and (f) cross section).

and CMC by differential spectrum analysis. It should be noted that plenty of ammonium cations are on the surface of QH and many carboxyl anions in CMC chains, which provided the possibility of cross-linking between $\mathrm{QH}$ and CMC. In addition, a number of hydroxy groups have been found in the surface of $\mathrm{QH}$ and $\mathrm{CMC}$. Therefore, hydrogen bonding and electrostatic attraction between the oppositely charged polymers are the driving force for the formation of tight and smooth films.

3.2. XRD Analysis. The X-ray diffraction patterns of $\mathrm{QH}$, $\mathrm{CMC}$, and blend films are shown in Figure 2. In the pattern of $\mathrm{QH}$, only one weak peak was shown at $19.8^{\circ}$, which was attributed to the hemicelluloses [38]. Two crystalline peaks are present at $2 \theta=18.9^{\circ}$ and $32.6^{\circ}$, which are the characteristic of cellulose I $[39,40]$. The XRD patterns of the blend films showed that the major diffraction peaks are at $2 \theta=19.7^{\circ}$, $32.5^{\circ}$, and $42.1^{\circ}$. This result indicated that the crystalline structure of the blend film appeared. The peak intensities and sites of QH/CMC films were different, which was due to the different amount of CMC in the blend film. The intermolecular hydrogen bonding and electrostatic interaction are the driving force of blend films between $\mathrm{QH}$ and $\mathrm{CMC}$ resulting in changing the crystal structure of the blend films.

3.3. Morphology of Blend Films. The SEM images of the surface and cross section of the blend films are presented in Figure 3. As can be seen, the surfaces of the blend films are smooth and homogeneous without remarkable discontinuities, cracks, or aggregates. In the cross-section images of the blend films, dense and smooth structures of blend films were obtained, which suggested that strong interaction force existed between $\mathrm{QH}$ and CMC. It is attributed to the diffusedness of $\mathrm{QH}$ and $\mathrm{CMC}$ and strong combination of the two components in the blend film. It could be partially explained that the blend films might have excellent mechanical properties.

3.4. UV-Vis Transparency of Blend Films. The thicknesses of all composite films were varied between 40 and $80 \mu \mathrm{m}$. 


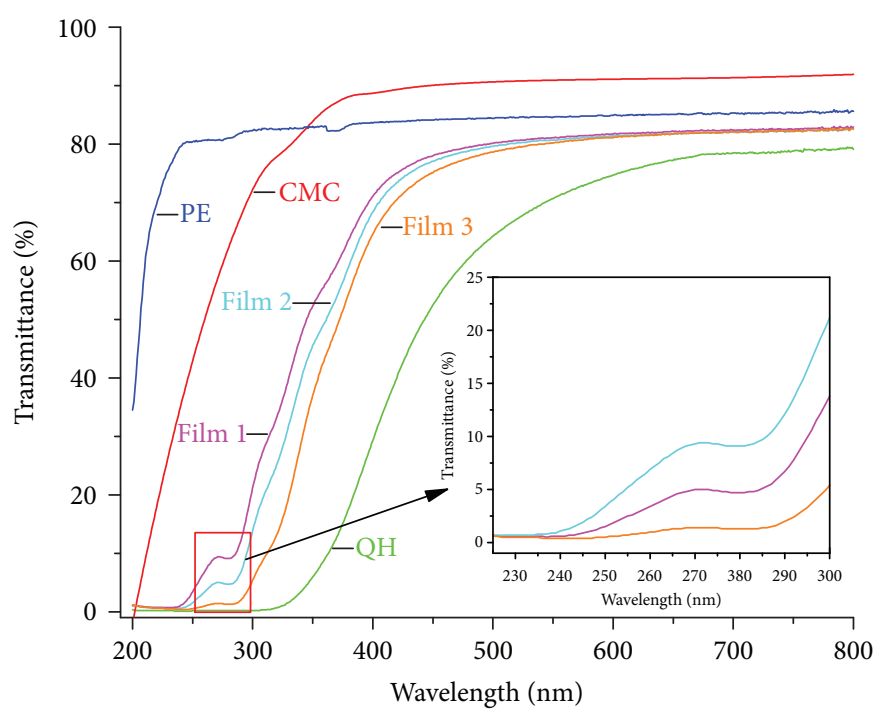

FIgURE 4: UV-Vis transmittance of the pure raw materials films, PE, and blend films.

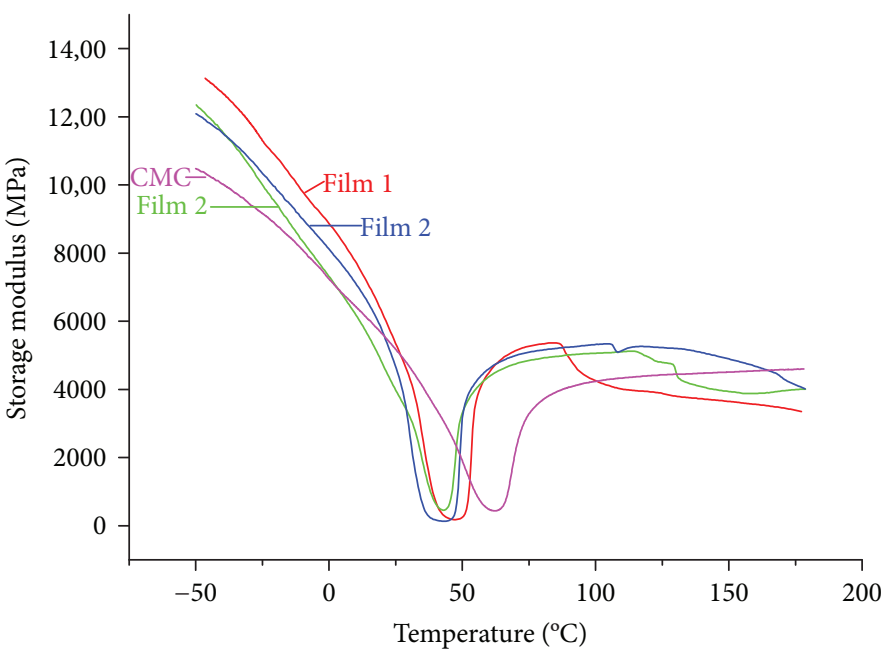

FIgURE 5: Storage modulus behavior of the pure CMC film and blend films.

Optical transmittance of polymer materials partly reflects the homogeneity of the structure and the interactions among various components. The light transmittances of pure material films and blend films at wavelength of $200-800 \mathrm{~nm}$ are shown in Figure 4. It can be found that the transmittance curve of each film rose gradually with increased wavelength and declined dramatic in UV light. The transmittance of pure CMC film reached 91.8\%; the QH film is the lowest and only reached $79.1 \%$. In addition, compared with pure QH film, each blend film has a high transmittance $(82.6 \%)$ in visible light, only a slightly lower than that of polyethylene (85.9\%). Moreover, the transparencies of the blend films increased with decreasing of the QH/CMC content ratio in UV light. It has the following order: film $2>$ film $1>$ film 3 . In other words, a relatively high content of CMC in the blend films is beneficial for transparency of the blend films, which due to the CMC is a water-soluble biopolymer and has a good film-forming property. These results indicated that the two polymers diffused uniformly and combined strongly. The transparency result is consistent with the SEM images. In addition, an interesting phenomenon occurred at the UV light of $280 \mathrm{~nm}$. A faint wave of film was present at $280 \mathrm{~nm}$ in the UV irradiation, which might be due to the absorption of the amino group [41].

3.5. Thermo-Mechanical Properties of Films. DMA is a versatile technique that complements the information provided by the more traditional thermal analysis techniques such as differential scanning calorimetry (DSC) and thermogravimetric analysis (TGA). The dynamic parameters such as storage modulus ( $\left.\mathrm{E}^{\prime}\right)$, loss modulus $\left(\mathrm{E}^{\prime \prime}\right)$, and damping factor $(\tan \delta)$ are temperature dependent and provide information about the interfacial bonding of the blend material [42].

The storage modulus curves of the pure CMC film and blend films are shown in Figure 5. It can be seen that the storage moduli of blend films and pure CMC film presents a 

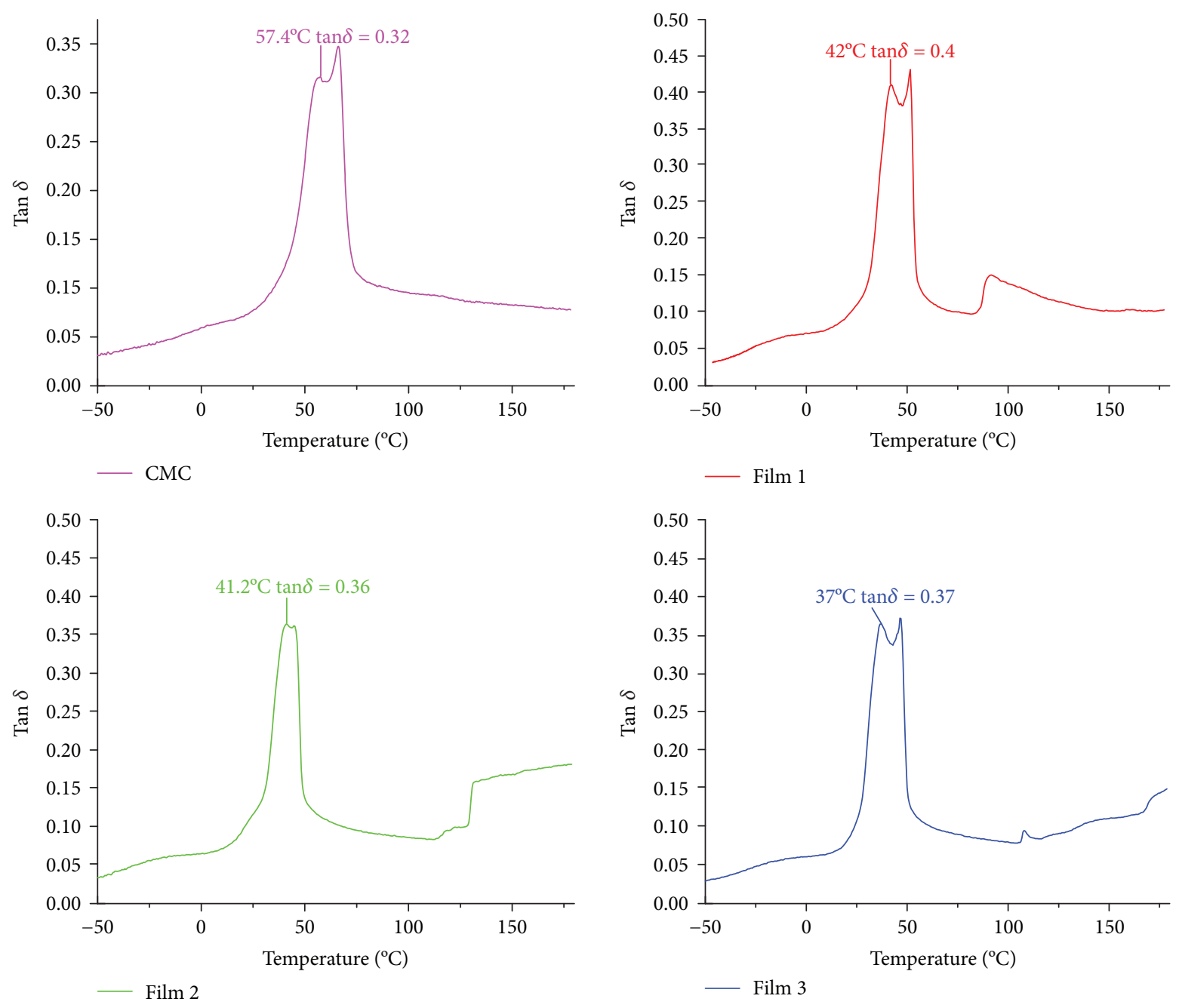

Figure 6: Tan $\delta$ behavior of the pure CMC film and blend films.

sharp decrease with increasing of temperature. The storage moduli of blend films and pure CMC film reached the minimum value around $46^{\circ} \mathrm{C}$ and $62^{\circ} \mathrm{C}$, respectively. The storage modulus was increased to a maximum around $98^{\circ} \mathrm{C}$ and then decreased, which was related to the evaporation of water in the blend films. The water can be used as a plasticizer in the mixed system. The storage modulus could be improved by a loss of water contents, which was due to that the interactions of two components have been enhanced. After the free water in films was evaporated, the storage modulus was decreased again with the increasing of the temperature. It could be associated with softening of the matrix. The $\tan \delta$ curves of pure CMC film and blend films are represented in Figure 6. All curves exhibit two relaxation peaks in a narrow temperature range (from 36 to $60^{\circ} \mathrm{C}$ ). It indicated that the glass transition temperature was influenced by moisture content. The $\tan \delta$ value was sensitive to molecular motion, and its peak represented the glass transition temperature. Therefore, it was important to point out that the moisture content of each film was equalized. In this study, the glass transition temperature could be defined as the temperature where the first peak of $\tan \delta$ presents. In general, broader and lower peak of $\tan \delta$ might demonstrate that the contents of blend films have been more diffused and less intense molecular motioned during glass transition process. Comparing the films, the glass transition temperature has the following order: $\mathrm{CMC}>$ film $2>$ film $1>$ film 3 , and the loss factor values have the following order: film $1>$ film $3>$ film $2>$ CMC. In addition, the dynamic mechanical behaviors of blend films were similar to the pure CMC film. These results indicated that the two biopolymers have been excellently diffused and strongly combined. Comparing the three blend films, film 2 has been excellently diffused and a higher degree of crosslinking. It has a great influence on the mechanical properties, and the mechanical property would be further investigated in the tensile testing.

To understand how CMC addition affects the thermal properties of the blend film, thermal properties of $\mathrm{QH}$, $\mathrm{CMC}$, and blend films were investigated by TGA under a nitrogen atmosphere. The typical TGA curves of $\mathrm{QH}$, $\mathrm{CMC}$, and blend films were shown in Figure 7(a). It can be seen that the rates of decomposition and weight loss of the blend films reached to the maximum during the temperature of $200-600^{\circ} \mathrm{C}$. Furthermore, the $T_{\text {onset }}$ (the temperature at 


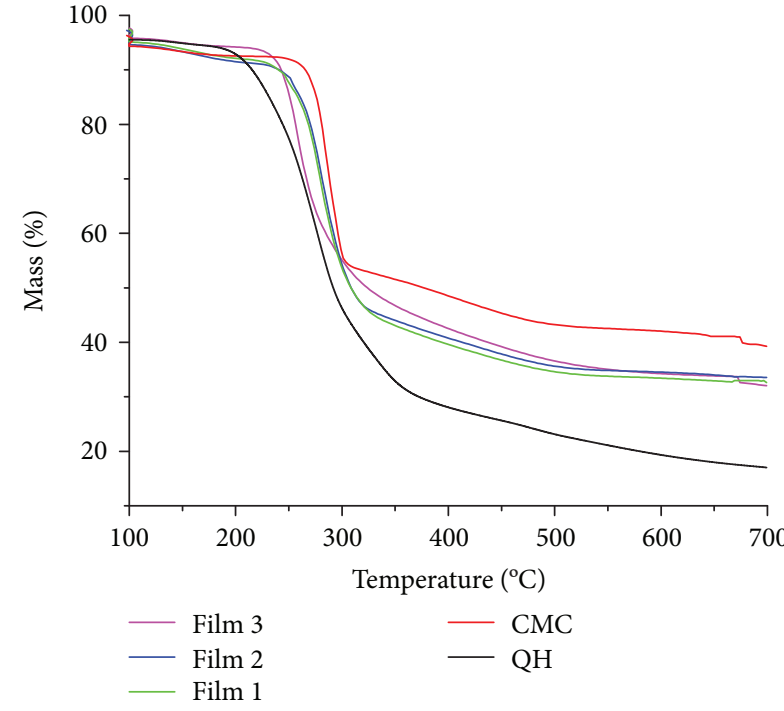

(a)

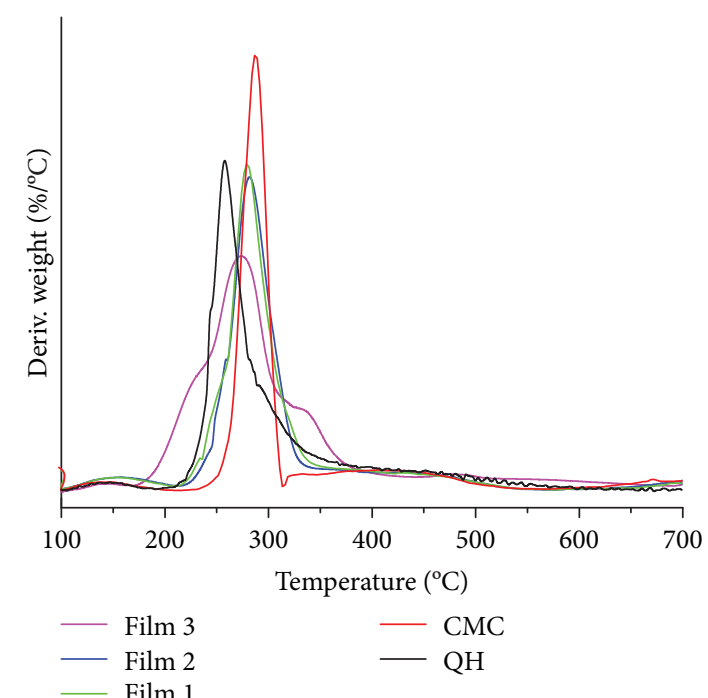

(b)

FIgure 7: TGA curves of the QH, CMC, and blend films (a). DTG curves of the QH, CMC, and blend films (b).

TABLE 2: Thermal characteristics of TG curves in Figure 7.

\begin{tabular}{lccc}
\hline Sample & $T_{\text {onset }}\left({ }^{\circ} \mathrm{C}\right)$ & $T_{1}\left({ }^{\circ} \mathrm{C}\right)$ & Residuals $($ wt $\%)$ at $700^{\circ} \mathrm{C}$ \\
\hline QH & 232.8 & 257.7 & 17.01 \\
CMC & 272.0 & 286.8 & 39.26 \\
Film 1 & 259.7 & 279.5 & 32.89 \\
Film 2 & 260.4 & 281.6 & 33.55 \\
Film 3 & 242.6 & 271.6 & 32.02 \\
\hline
\end{tabular}

the onset of the decomposition) and $T_{1}$ (the maximum weight loss temperature) of films were determined on the DTG curves (Figure $7(\mathrm{~b})$ ) as shown in Table 2. From Figure 7 and Table 2, it can be seen that the $T_{\text {onset }}$ and $T_{1}$ of the blend films were increased obviously with increasing of the CMC components. This result might be due to that the two components of the blend films were diffused homogeneously and have been strongly combined. In addition, the residuals $\left(\right.$ at $700^{\circ} \mathrm{C}$ ) of the blend films were increased with increasing of the CMC components, which implied that the addition of CMC contributed to thermal stability property. The thermodynamic properties of the blend films were affected directly by the partially crystalline polymer CMC. In general, the higher content of crystalline polymer in the blend system, the higher thermal stability and mechanical properties of films were obtained, which was evidenced by the results of tensile test and DMA.

The mechanical properties of blend films are of prime importance for various applications including packaging and coating. Therefore, all the films should be subjected to tensile testing in order to ensure that the films have sufficient physical performance. The results of tensile stress, tensile strain at break, and Young's modulus of PE, pure raw materials films, and blend films are shown in Table 3 , and the typical tensile stress-strain curves are presented in Figure 8. It is obviously seen that the tensile strength of the three blend films was much higher than that of the $\mathrm{PE}$ and $\mathrm{QH}$ films. The mechanical properties of $\mathrm{QH}$ film were greatly improved through cross-linking CMC. The tensile stress of blend films was increased with the decreasing of $\mathrm{QH}$ content, and the maximum stress was $65.2 \mathrm{MPa}$ of film 2. Moreover, the tensile strain at break and the ultimate tensile strength have the following order: film $2>$ film $1>$ film 3 . This result indicated that the mechanical properties of the blend films were greatly affected by the CMC content. This is due to that $\mathrm{CMC}$ is a crystalline polymer, which led to excellent mechanical properties of the blend films. In addition, with the CMC content increases, the interaction force between the two polymers was improved. That is to say, the two components have stronger bonding and a higher degree of cross-linking. The result of mechanical property is consistent with those of SEM, TG, and UV-Vis.

\section{Conclusions}

This study provided a novel way to prepare blend films based on QH and CMC. From the results of FTIR, XRD, and SEM, it was confirmed that there is a strong interaction force existed between $\mathrm{QH}$ and $\mathrm{CMC}$, and no chemical reaction occurred between QH and CMC. Furthermore, the films exhibited a good optical transmittance and mechanical properties, which would be beneficial for the applications of films as packaging and coating materials. From the results of SEM and DMA, it was found that the blend films have a good disperse and strong interface bonding. Moreover, the results of DMA revealed that the blend films have a low $\tan \delta$ and high storage modulus. The results of mechanical properties suggested that the addition of CMC contributed to mechanical properties by the strong electrostatic interactions and the enhanced hydrogen bonding with $\mathrm{QH}$. All those results suggested that the hemicellulose-based films might become attractive and green materials in the 
TABLE 3: Tensile testing results of the blend films.

\begin{tabular}{lcccc}
\hline Sample & Tensile strength $(\mathrm{MPa})$ & Tensile strain at break $(\%)$ & Young's modulus $(\mathrm{GPa})$ & Thickness $(\mu \mathrm{m})$ \\
\hline QH & $18.02 \pm 2.01$ & $1.30 \pm 0.50$ & $1.30 \pm 0.02$ & $80 \pm 2$ \\
CMC & $116.04 \pm 10.00$ & $17.2 \pm 1.21$ & $2.03 \pm 0.01$ & $50 \pm 8$ \\
PE & $11.21 \pm 1.30$ & $42.1 \pm 0.90$ & $0.03 \pm 0.03$ & $10 \pm 2$ \\
Film 1 & $55.02 \pm 0.61$ & $3.9 \pm 0.90$ & $1.54 \pm 0.43$ & $57 \pm 2$ \\
Film 2 & $65.21 \pm 5.23$ & $4.3 \pm 0.70$ & $1.60 \pm 0.40$ & $50 \pm 4$ \\
Film 3 & $54.22 \pm 7.90$ & $3.4 \pm 0.10$ & $1.59 \pm 0.18$ & $46 \pm 3$ \\
\hline
\end{tabular}

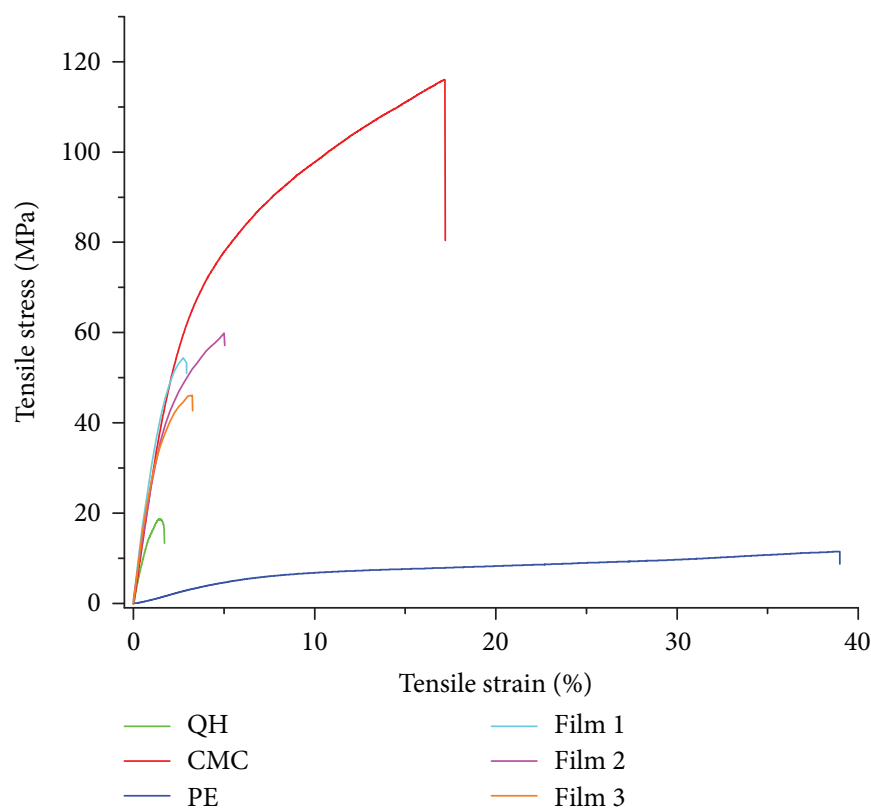

Figure 8: The tensile stress-strain curves of PE, pure raw material films, and blend films.

packaging, coating, and biomedicine application to replace the traditional petroleum-based materials.

\section{Data Availability}

Previously reported (Mw and DS of quaternized hemicelluloses) data were used to support this study and are available at DOI: $10.1021 / \mathrm{sc500124j}$, and the previously reported (the film preparation method) methods were used to support this study and are available at DOI: $10.3390 /$ ma9010004. This prior study is cited at relevant places within the text as references [30].

\section{Conflicts of Interest}

The authors declare that they have no conflicts of interest.

\section{Acknowledgments}

This work was supported by China Postdoctoral Science Foundation Grant (2016M601996), 13th Five-Year National Major Research and Development Program subtopic (2017YFD0600805), Introduction and Stability Talent Project of Anhui Agricultural University (yj201610), Anhui Science Foundation Grant (1808085MC68), Innovation and Entrepreneurship Training Project of Anhui University Student (201610364036), and Anhui Postdoctoral Science Foundation Grant (2017B157).

\section{References}

[1] U. Edlund, Y. Z. Ryberg, and A. C. Albertsson, "Barrier films from renewable forestry waste," Biomacromolecules, vol. 11, no. 9, pp. 2532-2538, 2010.

[2] L. Dai, R. Liu, L. Q. Hu, Z. F. Zou, and C. L. Si, "Lignin nanoparticle as a novel green carrier for the efficient delivery of resveratrol," ACS Sustainable Chemistry \& Engineering, vol. 5, no. 9, pp. 8241-8249, 2017.

[3] J. X. Sun, F. C. Mao, X. F. Sun, and R. C. Sun, "Comparative study of hemicelluloses isolated with alkaline peroxide from lignocellulosic materials," Journal of Wood Chemistry and Technology, vol. 24, no. 3, pp. 239-262, 2005.

[4] W. Boonkong, A. Petsom, and N. Thongchul, "Rapidly stopping hemorrhage by enhancing blood clotting at an opened wound using chitosan/polylactic acid/polycaprolactone wound dressing device," Journal of Materials Science: Materials in Medicine, vol. 24, no. 6, pp. 1581-1593, 2013. 
[5] L. S. Nair and C. T. Laurencin, "Biodegradable polymers as biomaterials," Progress in Polymer Science, vol. 32, no. 8-9, pp. 762-798, 2007.

[6] J. Pérez, J. Muñoz-Dorado, T. de la Rubia, and J. Martínez, "Biodegradation and biological treatments of cellulose, hemicellulose and lignin: an overview," International Microbiology, vol. 5, no. 2, pp. 53-63, 2002.

[7] M. Sadeghi and F. Soleimani, "Synthesis of novel polysaccharide-based superabsorbent hydro gels via graft copolymerization of vinylic monomers onto kappa-carrageenan," International Journal of Chemical Engineering and Applications, vol. 2, no. 5, pp. 304-306, 2011.

[8] F. H. A. Rodrigues, C. Spagnol, A. G. B. Pereira et al., "Superabsorbent hydrogel composites with a focus on hydrogels containing nanofibers or nanowhiskers of cellulose and chitin," Journal of Applied Polymer Science, vol. 131, no. 2, 2014.

[9] D. Klemm, B. Heublein, H. P. Fink, and A. Bohn, "Cellulose: fascinating biopolymer and sustainable raw material," Angewandte Chemie International Edition, vol. 44, no. 22, pp. 3358-3393, 2005.

[10] S. Zhang, W. Liu, J. Liang et al., "Buildup mechanism of carboxymethyl cellulose and chitosan self-assembled films," Cellulose, vol. 20, no. 3, pp. 1135-1143, 2013.

[11] C. Schmitt, C. Sanchez, S. Desobry-Banon, and J. Hardy, "Structure and technofunctional properties of proteinpolysaccharide complexes: a review," Critical Reviews in Food Science and Nutrition, vol. 38, no. 8, pp. 689-753, 1998.

[12] B. C. Saha, "Hemicellulose bioconversion," Journal of Industrial Microbiology \& Biotechnology, vol. 30, no. 5, pp. 279291, 2003.

[13] L. Bai, H. Hu, and J. Xu, "Influences of configuration and molecular weight of hemicelluloses on their paper-strengthening effects," Carbohydrate Polymers, vol. 88, no. 4, pp. 1258-1263, 2012.

[14] I. Egüés, A. Eceiza, and J. Labidi, "Effect of different hemicelluloses characteristics on film forming properties," Industrial Crops and Products, vol. 47, pp. 331-338, 2013.

[15] C. Péroval, F. Debeaufort, A. M. Seuvre, B. Chevet, D. Déspre, and A. Voilley, "Modified arabinoxylan-based films. Part B. Grafting of omega-3 fatty acids by oxygen plasma and electron beam irradiation," Journal of Agricultural and Food Chemistry, vol. 51, no. 10, pp. 3120-3126, 2003.

[16] N. M. L. Hansen and D. Plackett, "Sustainable films and coatings from hemicelluloses: a review," Biomacromolecules, vol. 9, no. 6, pp. 1493-1505, 2008.

[17] X. Peng, J. Ren, and R. Sun, “An efficient method for the synthesis of hemicellulosic derivatives with bifunctional groups in butanol/water medium and their rheological properties," Carbohydrate Polymers, vol. 83, no. 4, pp. 1922-1928, 2011.

[18] Z. Sárossy, T. O. J. Blomfeldt, M. S. Hedenqvist, C. B. Koch, S. S. Ray, and D. Plackett, "Composite films of arabinoxylan and fibrous sepiolite: morphological, mechanical, and barrier properties," ACS Applied Materials \& Interfaces, vol. 4, no. 7, pp. 3378-3386, 2012.

[19] A. Ebringerová, Z. Hromádková, M. Kačuráková, and M. Antal, "Quaternized xylans: synthesis and structural characterization," Carbohydrate Polymers, vol. 24, no. 4, pp. 301308, 1994.

[20] K. Schwikal, T. Heinze, A. Ebringerová, and K. Petzold, "Cationic xylan derivatives with high degree of functionalization," Macromolecular symposia, vol. 232, no. 1, pp. 49-56, 2005.
[21] J. L. Ren, F. Peng, and R. C. Sun, "Preparation of hemicellulosic derivatives with bifunctional groups in different media," Journal of Agricultural and Food Chemistry, vol. 56, no. 23, pp. 11209-11216, 2008.

[22] K. Petzold, K. Schwikal, W. Günther, and T. Heinze, "Carboxymethyl xylan - control of properties by synthesis," Macromolecular symposia, vol. 232, no. 1, pp. 27-36, 2005.

[23] K. Petzold, K. Schwikal, and T. Heinze, "Carboxymethyl xylan-synthesis and detailed structure characterization," Carbohydrate Polymers, vol. 64, no. 2, pp. 292-298, 2006.

[24] J. L. Ren, R. C. Sun, and F. Peng, "Carboxymethylation of hemicelluloses isolated from sugarcane bagasse," Polymer Degradation and Stability, vol. 93, no. 4, pp. 786-793, 2008.

[25] R. C. Sun, J. Tomkinson, J. C. Liu, and Z. C. Geng, "Oleoylation of wheat straw hemicelluloses in new homogeneous system,” Polymer Journal, vol. 31, no. 10, pp. 857-863, 1999.

[26] X.-F. Sun, R. C. Sun, and J. X. Sun, "Oleoylation of sugarcane bagasse hemicelluloses using $N$-bromosuccinimide as a catalyst," Journal of the Science of Food and Agriculture, vol. 84, no. 8, pp. 800-810, 2004.

[27] J. L. Ren, R. C. Sun, C. F. Liu, L. Lin, and B. H. He, "Synthesis and characterization of novel cationic SCB hemicelluloses with a low degree of substitution," Carbohydrate Polymers, vol. 67, no. 3, pp. 347-357, 2007.

[28] T. Bourtoom and M. S. Chinnan, "Preparation and properties of rice starch-chitosan blend biodegradable film," LWT - Food Science and Technology, vol. 41, no. 9, pp. 1633-1641, 2008.

[29] S. Mathew and T. E. Abraham, "Characterisation of ferulic acid incorporated starch-chitosan blend films," Food Hydrocolloids, vol. 22, no. 5, pp. 826-835, 2008.

[30] X. M. Qi, S. Y. Liu, F. B. Chu et al., "Preparation and characterization of blended films from quaternized hemicelluloses and carboxymethyl cellulose," Materials, vol. 9, no. 1, p. 4, 2016.

[31] F. Peng, J. L. Ren, F. Xu, J. Bian, P. Peng, and R. C. Sun, “Comparative study of hemicelluloses obtained by graded ethanol precipitation from sugarcane bagasse," Journal of Agricultural and Food Chemistry, vol. 57, no. 14, pp. 6305-6317, 2009.

[32] J. L. Ren, R. C. Sun, and C. F. Liu, "Etherification of hemicelluloses from sugarcane bagasse," Journal of Applied Polymer Science, vol. 105, no. 6, pp. 3301-3308, 2007.

[33] M. Kačuráková, N. Wellner, A. Ebringerová, Z. Hromádková, R. H. Wilson, and P. S. Belton, "Characterisation of xylantype polysaccharides and associated cell wall components by FT-IR and FT-Raman spectroscopies," Food Hydrocolloids, vol. 13, no. 1, pp. 35-41, 1999.

[34] M. Kačuráková, A. Ebringerová, J. Hirsch, and Z. Hromádková, "Infrared study of arabinoxylans," Journal of the Science of Food and Agriculture, vol. 66, no. 3, pp. 423-427, 1994.

[35] D. Hatanaka, K. Yamamoto, and J. I. Kadokawa, "Preparation of chitin nanofiber-reinforced carboxymethyl cellulose films," International Journal of Biological Macromolecules, vol. 69, pp. 35-38, 2014.

[36] L. Fan, M. Peng, X. Zhou et al., "Modification of carboxymethyl cellulose grafted with collagen peptide and its antioxidant activity," Carbohydrate Polymers, vol. 112, pp. 32-38, 2014.

[37] M. Yadollahi, H. Namazi, and S. Barkhordari, "Preparation and properties of carboxymethyl cellulose/layered double hydroxide bionanocomposite films," Carbohydrate Polymers, vol. 108, pp. 83-90, 2014. 
[38] X. W. Peng, J. L. Ren, L. X. Zhong, and R. C. Sun, "Nanocomposite films based on xylan-rich hemicelluloses and cellulose nanofibers with enhanced mechanical properties," Biomacromolecules, vol. 12, no. 9, pp. 3321-3329, 2011.

[39] A. J. Svagan, M. A. S. Azizi Samir, and L. A. Berglund, "Biomimetic polysaccharide nanocomposites of high cellulose content and high toughness," Biomacromolecules, vol. 8, no. 8, pp. 2556-2563, 2007.

[40] P. Tingaut, T. Zimmermann, and F. Lopez-Suevos, "Synthesis and characterization of bionanocomposites with tunable properties from poly(lactic acid) and acetylated microfibrillated cellulose," Biomacromolecules, vol. 11, no. 2, pp. 454464, 2010.

[41] F. S. Rodembusch, F. P. Leusin, L. F. Campo, and V. Stefani, "Excited state intramolecular proton transfer in amino 2-(2'hydroxyphenyl) benzazole derivatives: effects of the solvent and the amino group position," Journal of Luminescence, vol. 126, no. 2, pp. 728-734, 2007.

[42] J. Guan, Y. Wang, B. Mortimer et al., "Glass transitions in native silk fibres studied by dynamic mechanical thermal analysis," Soft Matter, vol. 12, no. 27, pp. 5926-5936, 2016. 


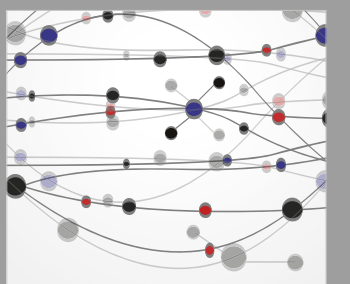

The Scientific World Journal
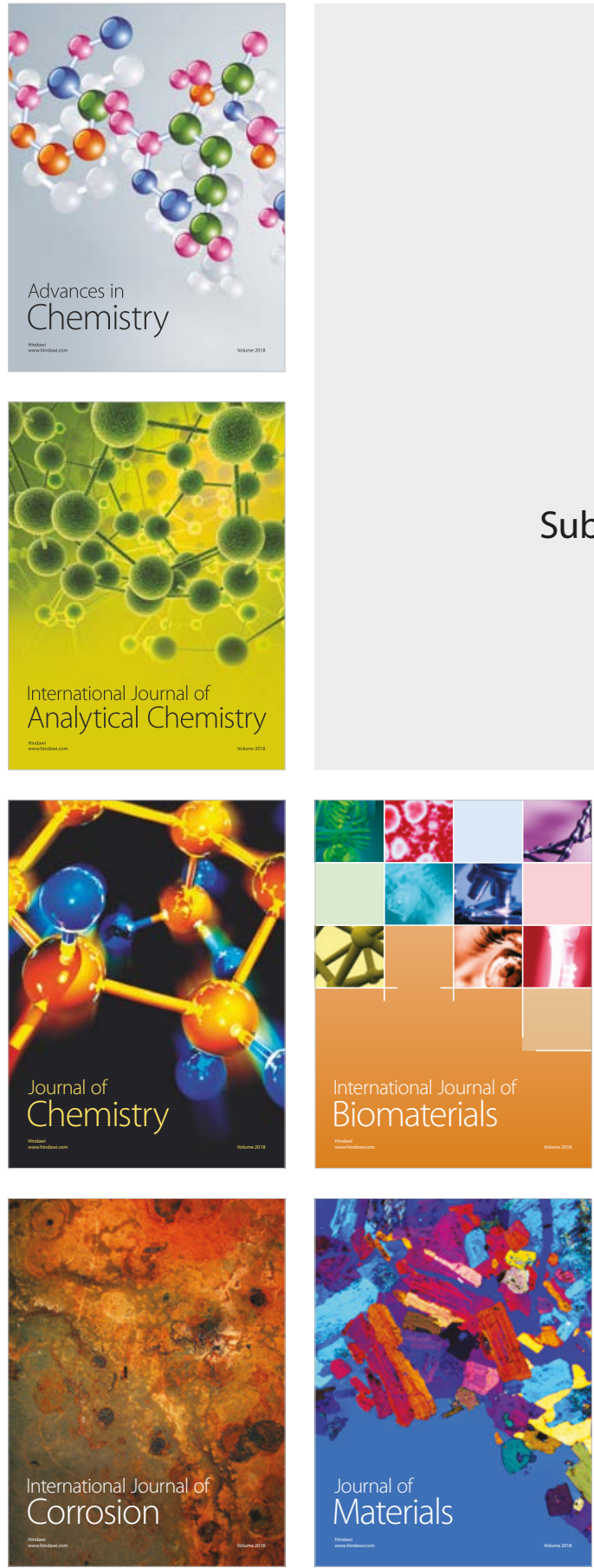

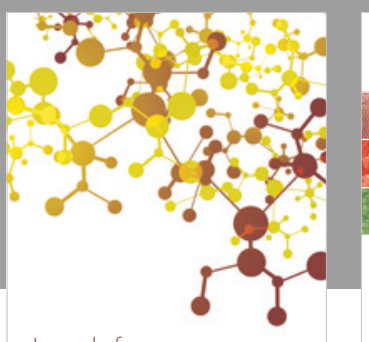

Journal of

Applied Chemistry
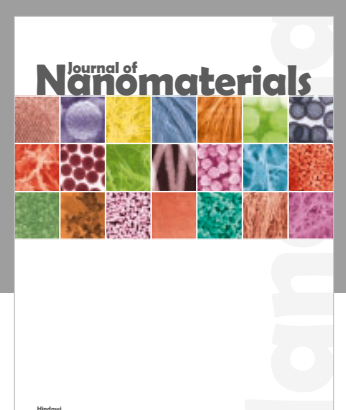

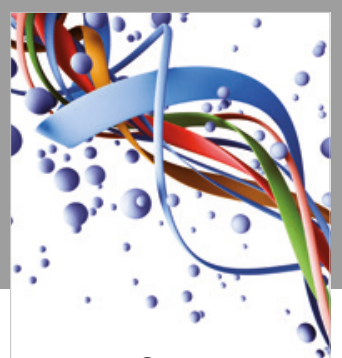

Scientifica

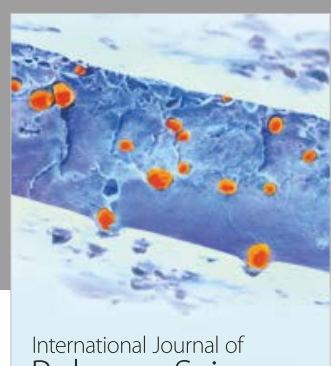

Polymer Science

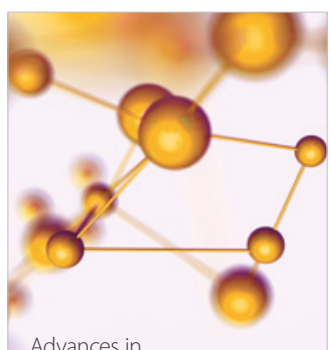

Physical Chemistry
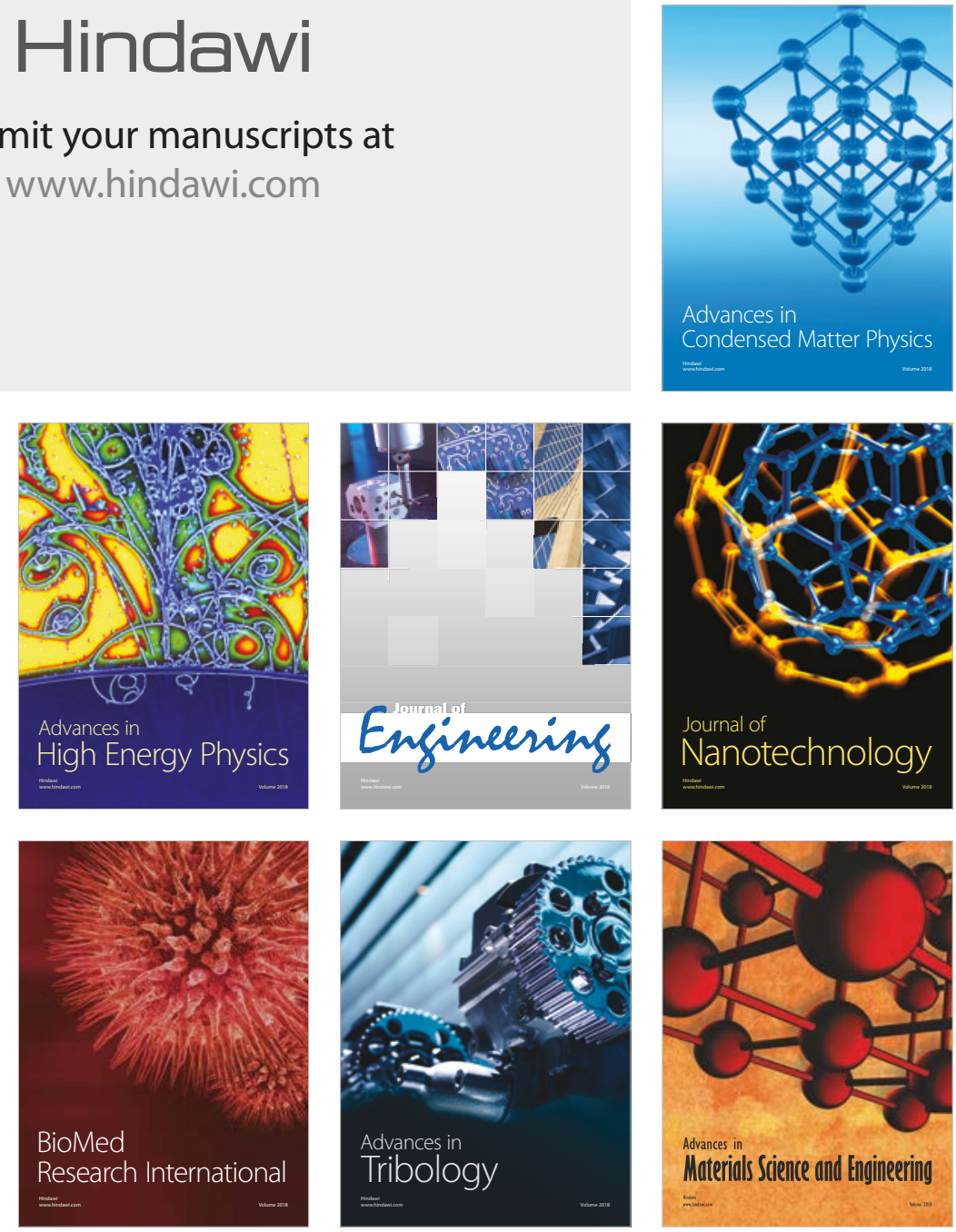